\title{
Three new species of the Fannia serena species subgroup from China (Diptera: Fanniidae)
}

\author{
Mingfu Wang*, Fenglin Song \& Xiaolan Cheng
}

Wang, M. F., Song, F. L. \& Cheng, X. L. 2017: Three new species of the Fannia serena species subgroup from China (Diptera: Fanniidae). — Entomol. Fennica 28: $67-74$.

The Fannia serena species group (Diptera: Fanniidae) is mainly distributed in the Holarctic region and comprises four subgroups with a total of 32 species. Three new species of the Fannia serena-subgroup, Fannia aureomarginata Wang et Cheng, sp. n., F. suberemna Wang, sp. n. and F. wui Wang, sp. n., are described from China. An identification key to all known species of the Fannia serena-subgroup is also provided.

M. F. Wang, Institute of Entomology, Shenyang Normal University, Shenyang 110034, P. R. China; *Corresponding author's e-mail: wangmingfu403@163. com

F. L. Song \& X. L. Cheng, Liaoning Entry-Exit Inspection and Quarantine Bureau, Dalian 116001, P. R. China.

Received 3 February 2016, accepted 22 November 2016

\section{Introduction}

The genus Fannia Robineau-Desvoidy, 1830 (Diptera: Fanniidae) is a species rich genus of flies. The Fannia serena-group was erected by Chillcott in 1961 and then reviewed and further defined by later specialists (Hennig 1965, Pont 1965, Rozkošný et al. 1997, Wang et al. 2006). The $F$. serena-group now comprises 4 subgroups, one of which is the $F$. serena-subgroup. The species of Fannia serena-subgroup are distributed in the Holarctic and the northern margin of the Oriental regions.

The taxa of the Fannia serena-subgroup share the following diagnostic characters: the presutural acrostichal setulae are commonly biserial (rarely triserial), the lower calypter is linear in shape, the mid femur is without spine-like setae anteroventrally, the hind coxa is without setae posteroventrally, the hind femur is without posteroventral setae in the distal part, the tibiae are usually with a single seta (except for a few species), the abdomen is broadest on the posterior margin of the syntergite $1+2$, and the male cerci are often in the shape of an inverted $\mathrm{T}$ in the posterior view.

In this paper, three new species of the F. sere$n a$-subgroup are described from China and a key to the 32 known species (including the three new species) of the subgroup is given.

\section{Materials and methods}

The specimens examined in this study were collected by sweeping from brushwood with hand nets. The external morphology was observed under a stereoscopic microscope and metric characters were measured with an ocular micrometer. To observe the detailed characters of the male terminalia, these organs were detached from the body, cleared by warming in a $10 \% \mathrm{KOH}$ solution (at approximately $100{ }^{\circ} \mathrm{C}$ ) for several minutes, placed in a droplet of glycerol, and observed un- 
der a compound light microscope. The type specimens of the new species are deposited in the Institute of Entomology, Shenyang Normal University (IESNU), Shenyang, Liaoning Province, China.

The morphological terminology follows McAlpine (1981). Absolute measurements are used for body length in millimeters ( $\mathrm{mm}$ ). Abbreviations used for characters are:

- For setae: $a c r=$ acrostichal, $a d=$ anterodorsal, $a v=$ anteroventral, $d=$ dorsal, $d c=$ dorsocentral, $i a l=$ intra-alar, $p=$ posterior,$p d$ $=$ posterodorsal, $p v=$ posteroventral, $p r a=$ prealar

- For veins: $\mathrm{Sc}=$ subcosta, $\mathrm{Rs}=$ radial node, $\mathrm{M}$ $=$ medial, $\mathrm{dm}-\mathrm{cu}=$ discal medial-cubital, $\mathrm{R}_{4+5}$ $=$ branch of radius, $\mathrm{r}-\mathrm{m}=$ radial - medial crossvein.

\section{Taxonomy}

\subsection{Descriptions}

\subsubsection{Fannia aureomarginata Wang \& Cheng, sp. n.}

Material. Holotype: đ̂, P. R. China, Yunnan, Mt. Yulong, 3,200 m, 24.V.2007, S. C. Bai leg. (IESNU).

Diagnosis. The new species resembles Fannia wui sp. n, but differs from it in having calypters brown, margins rather golden, hind tibia with $2 a v$ and 3-5 ad, frontal setae 12-13, arista longer, prementum longer, pra shorter, and $\delta$ tergite 5 blunter, with rows of stout spine in the posterior part. The new species resembles also Fannia setifemorata, but differs from it in having scutum with dark brown pruinosity, mid tibia with 3-4 $p d$, halteres black, wing-base concolourous, basicosta brown, pra shorter, and $\widehat{o}$ tergite 5 blunter, with stout spines in the posterior part.

Description. Male: Body length $5.0 \mathrm{~mm}$. Head: Eye with thin and short hairs, facets enlarged on anterior margin in upper part; occipital setae uniserial, long and curved towards anterior in upper half, longest occipital setae on vertex slightly shorter than ocellar bristles, and gradually shorter to both sides; upper part of head with 2 rows of occipital-orbital bristles behind occipi- tal setae; upper part of fronto-orbital plate with thick golden-brownish pruinosity, lower part and fronto-orbital plate with silver-grey pruinosity, median part of frons about 2 times as wide as width of anterior ocellus, and about $3 / 4$ of width of first antennal flagellomere; frontal vitta black, narrowest part about equal to width of one frontoorbital plate, frontal setae 12-13, strong, on lower margin of ocellar triangle, upper orbital setae absent; fronto-orbital plate bare, median part about $2 / 5-1 / 3$ of width of first antennal flagellomere; antennae black, first flagellomere 1.5 times as long as wide, arista black, swollen at base, pubescent, longest hair about as long as its basal diameter; epistoma not projecting beyond vibrissal angle, vibrissal angle behind frontal angle in profile; peristomal setae uniserial, outside with uniserial short bristles, gena and postcranium with black hairs, in upper part of gena without setae, proboscis of medium length, labellum developed, prementum with thin greyish-yellow pruinosity, slightly shining, about 2 times as long as high; palpus black, long, about as long as prementum. Thorax: ground-colour black, scutum with dark brown pruinosity, without stripes, acr biserial, strong, a pair of prescutellar setae stout; distance between two $a c r$ rows narrower than distance between outer $a c r$ row and $d c$ row, $d c 2+3$, ial $0+2$, pra 2, (one side 3 ) anterior one strongest, about $1 / 2$ of length of posterior notopleural seta, notopleura without setulae, proepisternal setae 2, prostigmatal seta 1, and around it with 9-10 long setulae, basisternum, proepisternal depression, anepimeron, meron and katepimeron bare, katepisternal setae 1:1, katepisternum without ventral spines, only with usual setae; anterior spiracle yellow, posterior one dark brown; calypters brown, margins goldish, lower one linear, not projecting beyond upper one. Wings brownish, wing-base concolourous, tegula dark brown, epaulet black, basicosta brown, costal spine inconspicuous, vein Sc not curved bow-like; node of Rs bare on ventral and dorsal surfaces; vein $M$ straight, vein $M$ parallel to vein $\mathrm{R}_{4+5}$ in distal part, vein r-m slightly thickened, vein dm-cu straight, crossveins without obvious cloud, halteres black. Legs: black, only base of fore tibia yellow, ventral edge of fore coxa without spine on anterior margin, fore femur with complete $p v$ rows, fore tibia without $a d$ and median $p$, first fore tarsomere with 

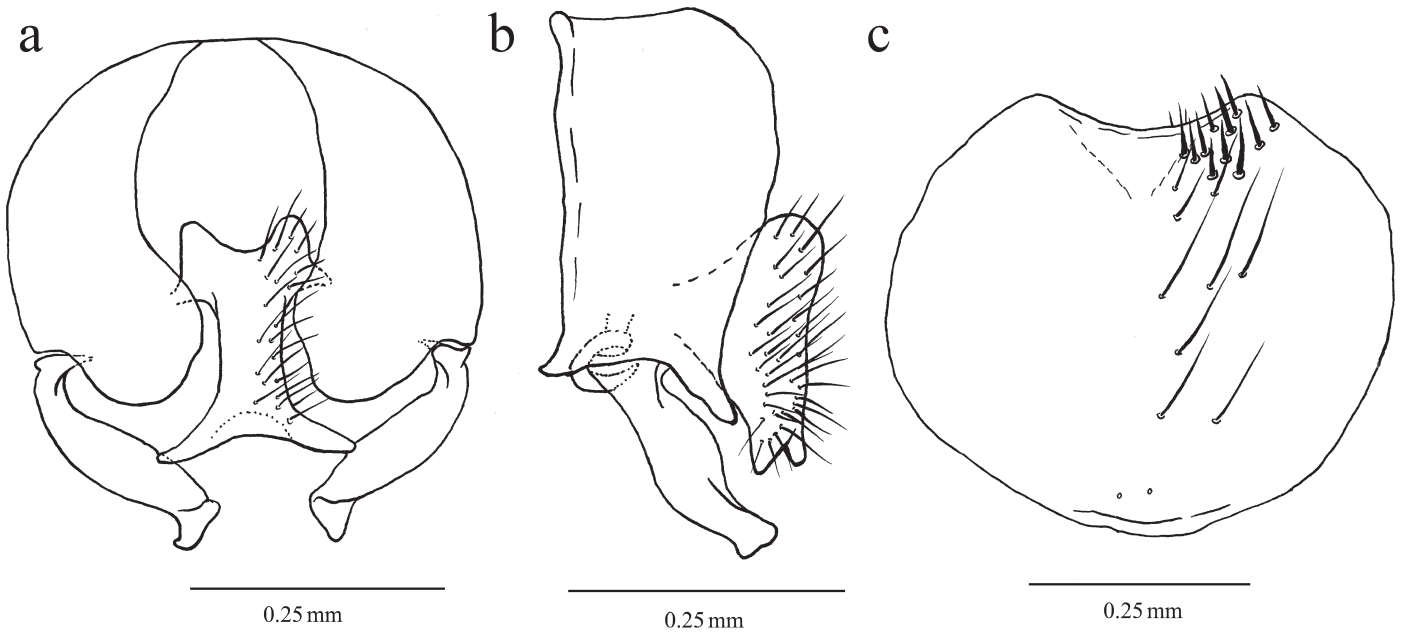

Fig. 1. Fannia aureomarginata Wang \& Cheng, sp. n. (male holotype). - a. Terminalia, posterior view. - b. Terminalia, lateral view, - c. $5^{\text {th }}$ sternite, ventral view.

1-2 long setae in basal part ventrally; length of first tarsomere about $2 / 5$ of length of fore femur, fore tarsomere without light patch, mid coxa without any hooked spines or spine-like setae, mid femur with $a v$ row, sparse and long in basal part, towards apex gradually becoming shorter and denser, and becoming comb-like in distal 1/3, without gaps; $p v$ row biserial in middle, with one slender complete $p$ row in upper part; mid tibia not more swollen than fore and hind tibiae, slightly swollen in distal half, with short fine hairs on ventral surface, longest apical hairs about equal to width of mid tibia, with 3 stout $a d, 3-4$ $p d$, mid first tarsomere without special structure; hind coxa bare on posterior and inner margin, hind femur with a complete av row, 1 stout subapical seta longer than width of hind femur, $p v$ in basal 2/3, short except for 1-2 in basal part, others not longer than width of hind femur, hind tibia with $2 a v, 2-3 a d, 1$ median $d$, some erect setulae on posterior surface, hind tarsomere without special structure. Abdomen: oval, flat, tergites with thick greyish-yellow pollinosity, slightly brown pollinosity, tergites $2-4$ each with a median inverted " $T$ " vitta, tergite 5 with a dark median stripe, sternite 1 bare, tergites $2-4$ with many long setae, sternite 5 and terminalia as shown in Fig. 1.

Etymology. The specific name refers to the goldish margins of calypters.

Distribution. P. R. China, Yunnan, Mt. Yulong (type locality).

\subsubsection{Fannia suberemna Wang, sp. n.}

Material. Holotype: ふૈ, P. R. China, Ningxia, Jingyuan, Tawan, 1,856 m, 2.VII.2008, M. F. Wang leg. (IESNU). Paratype: $1 \hat{\jmath}$, P. R. China, Ningxia, Jingyuan, Mt. Baiyun, 2,200 m, 27.VI.2008, leg. M. F. Wang leg. (IESNU).

Diagnosis. The new species resembles Fannia eremna, but differs from it in having hind femur without $p v$, pra short, frontal setae 7-10, the base of basal fore tibia yellow; the distal part of mid tibia with long hairs, cerci not cavate in the distal part but slightly exserted in the middle part, surstylus slender, and the width of tergite 5 longer than the length.

Description. Male: Body length 4.0-4.5 mm. Head: Eye with thin and short hairs, facet enlarged on anterior margin in upper part; occipital setae uniserial, long and curved towards anterior in upper half, longest occipital setae on vertex, equal to or slightly shorter than ocellar bristles, upper part of head with 2 rows of occipital-orbital bristles behind occipital setae; upper part of fronto-orbital plate with thick brown pruinosity, lower part and fronto-orbital plate with grey pruinosity, median part of frons about $3 / 4$ of distance of posterior ocellus, and about $3 / 4$ of width of first antennal flagellomere; frontal vitta black, with light grey pruinosity, disappeared in the narrowest part, frontal setae $7-10$, on lower $3 / 4$ of frons, upper orbital setae absent; fronto-orbital plate bare, median part about $2 / 5$ of width of first 

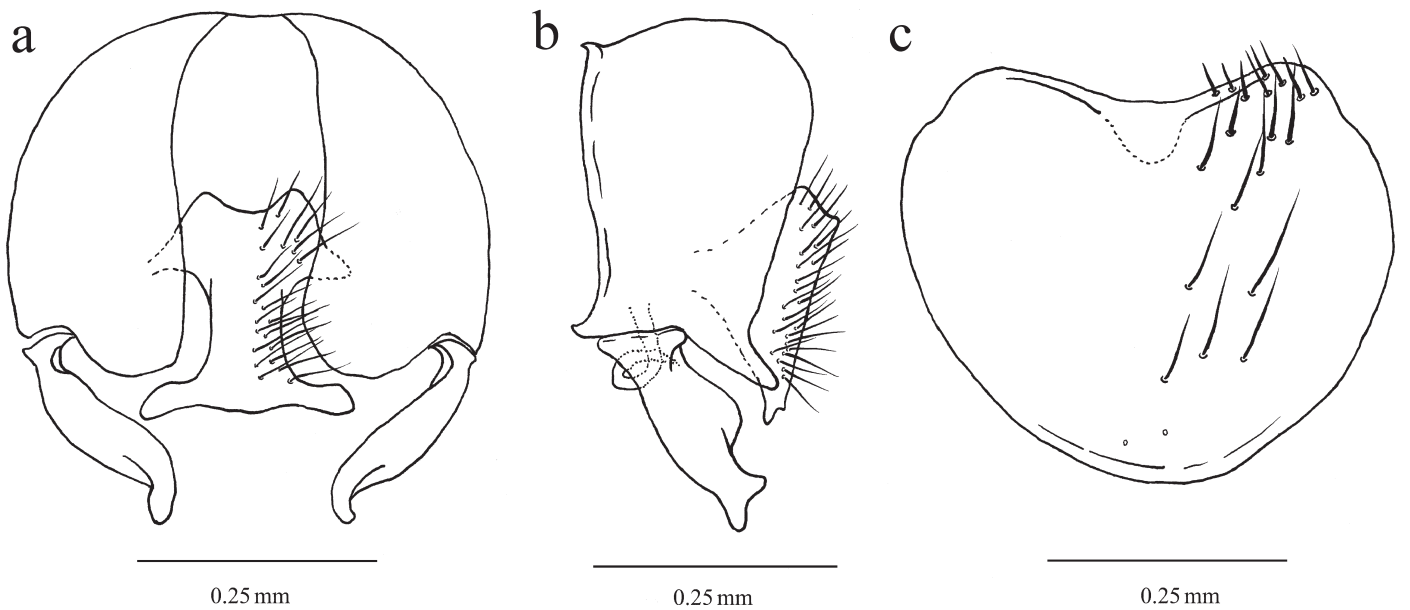

Fig. 2. Fannia suberemna Wang, sp. n. (male holotype). - a. Terminalia, posterior view. - b. Terminalia, lateral view. - c. $5^{\text {th }}$ sternite, ventral view.

antennal flagellomere, antennae black, first flagellomere 1.5 times as long as wide, arista black, swollen at base, pubescent, longest hair no longer than its basal diameter; epistoma not projecting beyond vibrissal angle, vibrissal angle behind frontal angle in profile, peristomal setae uniserial, outside with some short bristles, gena and postcranium with black hairs, in upper part of gena without setae, prementum with thin greyishyellow pruinosity, slightly shining, about 2.5 times as long as high; palpus black, rodlike, about as long as prementum. Thorax: ground-colour black, with grey-yellowish pruinosity in side, scutum with dark brown pruinosity, without obvious stripes, acr biserial, strong, a pair of prescutellar setae stout; distance between two acr rows narrower than distance between outer $\mathrm{acr}$ row and $d c$ row, $d c 2+3$, ial $0+2$, pra 2, (one side 3 ) anterior one strongest, about $1 / 3$ of length of posterior notopleural seta, notopleura without setulae, proepisternal setae 2 , prostigmatal seta 1 (with 1 stout seta in lower part), and around it 7-9 long setulae, basisternum, proepisternum, anepimeron, meron and katepimeron bare, katepisternal setae 1:1, katepisternum without ventral spines, only with some short setae; anterior spiracle yellow, small, posterior one brown; calypters dark brown, margins concolourous, lower one linear, not projecting beyond upper one. Wings: brownish, wing-base concolourous, tegula dark brown, epaulet black, basicosta brown, costal spine conspicuous, slightly longer than around spine; vein Sc not curved bow-like, node of Rs bare on ventral and dorsal surfaces, vein $M$ straight, vein $\mathrm{M}$ parallel to vein $\mathrm{R}_{4+5}$ in distal part, vein $\mathrm{r}-\mathrm{m}$ slightly thickened, vein dm-cu slightly convex in middle, crossveins without obvious cloud, halteres black brown. Legs: black, only base of fore tibia yellow; ventral edge of fore coxa without spine on anterior margin, fore femur with complete $p v$ rows, fore tibia without $a d$ and median $p$, first fore tarsomere with 1-2 long setae in basal part ventrally; fore tarsomere without light patch, mid coxa without hooked spines or spinelike setae, mid femur with $a v$ row, sparse and long in basal part, towards apex gradually becoming shorter and denser, with a vacancy at subapical part, with 4-5 straight setae in distal part; $p v$ row biserial in middle, with one slender complete $p$ row in upper part; mid tibia slightly swollen in distal half, not more swollen than others, with short fine hairs on ventral surface, longest apical hairs about equal to width of mid tibia, with $1 \mathrm{ad}$ and $p d 1$ in distal part, mid first tarsomere without special structure; hind coxa bare on posterior and inner margin, hind femur with short setaceous $a v$ row in basal part, 2-4 in distal part obviously strong, 2-3 in distal 1/3 long, at least 2 av longer than width of hind femur, $p v$ absent, with some short setae in posterior ventral basal and dorsal parts, the rest all bare, hind tibia with $1 a v, 1 a d, 1$ median $d$, hind tarsomere without special structure. Abdomen: oval, flat, ground-colour black, tergites with thick greyish-brown pollinosity, 
Tergite 2 and 3 with large median triangular spot, tergite 5 with a dark median stripe, wider in basal part, each tergite side with stout setae; sternite 1 bare, sternite 5 and terminalia as shown in Fig. 2.

Etymology. The specific name refers to the similarity of the new species and F. eremna Chillcott.

Distribution. P. R. China, Ningxia, Jingyuan (type locality).

\subsubsection{Fannia wui Wang, sp. n.}

Material. Holotype: §ิ, P. R. China, Ningxia, Jingyuan, Mt. Dingshan, 2,200 m, 27. VI.2008, M. F. Wang leg. (IESNU). Paratype: $1 \hat{\jmath}$, P. R. China, Ningxia, Longde, Sutai, 2,150 m, 26.VI.2008, M. F. Wang leg. (IESNU).

Diagnosis. The new species resembles Fannia setifemota, but differs from it in having calypters and halteres dark brown, hind tibia with $1 a v$, the length of $p v$ shorter than the width of hind femur, apical hairs of mid tibia on the ventral surface shorter than the width of mid tibia, wingbase concolourous, fronto-orbital plate narrower, not cavate in distal part but slightly exserted in the middle part, the middle of surstylus broad in profile, the margin of tergite 5 parallel in the middle, without stout spine rows in the posterior part. The new species resembles also Fannia tripla, but differs from it in having broad frons, frontal setae 8 10 , first antennal flagellomere about 1.5 times as long as wide, apical hairs of mid tibia on the ventral surface shorter, hind tibia with 3-5 $a d, p v$ in the basal $3 / 5$ of hind femur, the middle of cerci thin in profile.

Description. Male: Body length $4.8 \mathrm{~mm}$. Head: Eye with thin and short hairs, facet enlarged on anterior margin in upper part; occipital setae uniserial, long and curved towards anterior in upper half, occipital setae on vertex slightly shorter than ocellar bristles, with 1-2 rows occipital-orbital setae behind occipital setae; upper part of fronto-orbital plate with thick golden-brownish pruinosity, lower part and fronto-orbital plate with silver-grey pruinosity, median part of frons narrower than distance of anterior ocellus from exterior margin, and about $3 / 4$ of width of first antennal flagellomere; frontal vitta black, narrowest part linear, frontal setae 8-10, situated on lower margin of ocellar triangle, with some small hairs between them in lower part, fronto-orbital plate bare, median part about $2 / 5$ of width of first antennal flagellomere, antennae black, first flagellomere 1.5 times as long as wide, arista black, swollen at base, short pubescent, longest hair about no longer than its basal diameter; epistoma not projecting beyond vibrissal angle, vibrissal angle behind frontal angle in profile, peristomal setae uniserial, outside with uniserial short bristles, gena and postcranium with black hairs, upper part of gena without setae, proboscis stout, labellum developed, prementum with thin greyish-brown pruinosity, slightly shining, about 1.5 times as long as high; palpus black, rodlike, longer than prementum. Thorax: ground-colour black, scutum and lateral surface with dark brown pruinosity, without stripes, acr biserial, strong, a pair of prescutellar setae stout; distance between two $a c r$ rows narrower than distance between outer $a c r$ row and $d c$ row; $d c 2+3$, ial $0+2$, pra 2 , anterior one strongest about $3 / 5$ of length of posterior notopleural seta; notopleura without setulae, proepisternal setae 2 , prostigmatal seta 1 , and around it with 12-14 long setulae, basisternum, proepisternum, anepimeron, meron and katepimeron bare, katepisternal setae 1:1, katepisternum without ventral spines, only with long setae; anterior spiracle light yellow, posterior one dark brown; calypters dark brown, margins concolourous, lower one linear, not projecting beyond upper one. Wings brownish, wing-base concolourous, only with a white patch in basal part, tegula dark brown, epaulet black, basicosta brown, costal spine inconspicuous, vein Sc not curved bow-like, node of Rs bare on ventral and dorsal surfaces, vein $\mathrm{M}$ straight, vein $\mathrm{M}$ parallel to vein $\mathrm{R}_{4+5}$ in distal part, vein $\mathrm{r}-\mathrm{m}$ slightly thickened, vein dm-cu slightly convex forward in middle, crossveins without obvious cloud, halteres black brown. Legs: entirely black, ventral edge of fore coxa without spine on anterior margin, fore femur with complete $p v$ rows, fore tibia without $a d$ and median $p$, first fore tarsomere with 1-2 long setae in basal part ventrally; length of first tarsomere about $2 / 5$ length of fore femur, fore tarsomere without light patch, mid coxa without any hooked spines or spine-like setae, mid femur with $a v$ row, sparse and long in basal part, towards apex gradually becoming shorter and denser, and becoming comb-like in distal $1 / 3$, without gaps; $p v$ biserial in middle, with one complete $p$ row in 

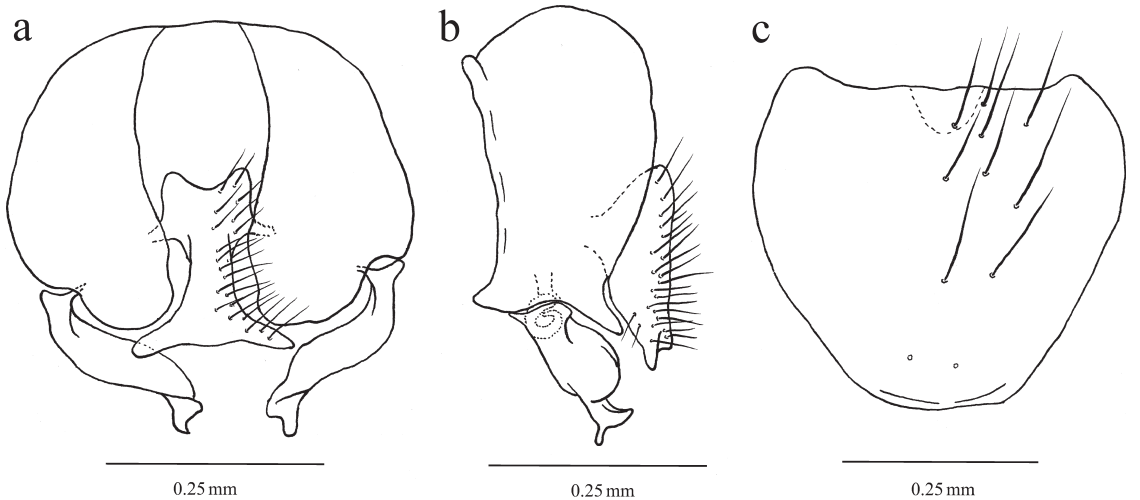

Fig. 3. Fannia wui Wang, sp. n. (male holotype). - a. Terminalia, posterior view. - b. Terminalia, lateral view. - c. $5^{\text {th }}$ sternite, ventral view.

upper part; mid tibia not more swollen than others, slightly swollen in distal half, with short fine hairs on ventral surface, longest apical hairs slightly shorter than width of mid tibia, with 3-4 $a d, 2-4 p d$, mid first tarsomere without special structure; hind coxa bare on posterior and inner margin, $a v$ row of hind femur short in basal part, and long in distal part, the one in subapical part longest, longer than width of hind femur, $p v$ in basal 3/5-2/3, length shorter than width of hind femur, hind tibia with $1 a v, 3-5 a d$, median $1 d$, hind tarsomere without special structure. Abdomen: oval, flat, ground-colour black, tergites with thick greyish-brown pollinosity, tergites 2 and 3 with more brownish pollinosity, each with large median triangular spot, each tergite side with stout setae; especially sides of $1^{\text {st }}$ and $2^{\text {nd }}$ syntergite, distal part of these setae hooked, sternites 24 with dark median triangular spot, sternites 5 with a dark median stripe, sternite 1 bare, sternites 2-4 with many long setae, sternites 5 and terminalia as shown in Fig. 3.

Etymology. The species is named according to professor Yuxiao $\mathrm{Wu}$.

Distribution. P. R. China, Ningxia, Jingyuan (type locality).

\subsection{Key to the known species of the Fannia serena-subgroup (males)}

1. Frons narrow, median part at most as wide as first antennal flagellomere

2

- Frons broad, median part about 1.5 times as wide as first antennal flagellomere

F. diploura Wang, Xue \& Zhang, 2006
2. Pra 1

- Pra2 (at least 2 on one side) 6

3. Tibiae yellow 4

- Tibiae black 5

4. Thorax and abdomen black, abdomen with obvious triangular marks

F. pallitibia (Rondani, 1866)

- Thorax and abdomen grey, abdomen with a narrow black median longitudinal stripe

F. pruinosa (Meigen, 1826)

5. Fronto-orbital plates almost contiguous

F. similis (Stein, 1895)

- Fronto-orbital plates separated by a distinct frontal vitta F. bradorei Chillcott, 1961a

6. Hind tibia with more than 1 seta on $\begin{array}{ll}\text { anteroventral or anterdorsal surface } & 7\end{array}$

- Hind tibia with $1 \mathrm{av}$ and $1 \mathrm{ad} \quad 12$

7. Hind tibia with $1 \mathrm{ad}$, mid tibia with $3 \mathrm{ad}$, calypters infuscated, halteres dark brown, frontal setae 11-14 F. tripla Nishida, 1975

- Hind tibia with 2-5 ad 8

8. Hind tibia with $2 a v \quad 9$

- Hind tibia with 1 av $\quad 11$

9. Mid tibia with $1 \mathrm{ad}$, hind tibia with 1 ad F. ampla Nishida, 1994

- Mid tibia with 3 ad

10. Mid tibia with 3-4 pd, haltere brownish, basicostal scale dark brown, pra short, about $1 / 2$ length of notopleural setae

F. aureomarginata Wang \& Cheng, sp. n.

- Mid tibia with $2 p d$, haltere brownish-yellow, basicostal scale brownish-yellow, pra about 2/3 length of notopleural setae

F. setifemorata Wang, Xue \& Zhang, 2006

11. Upper calypter and haltere fuscous, legs 
black, first antennal flagellomere about 1.5 times as long as wide, length of prementum about 1.5 times as long as high, mid tibia with 2-4 pd, hind margin of $5^{\text {th }}$ sternite broad, surstylus of terminalia short and wide in profile $\quad$ F. wui Wang, sp.n.

- Upper calypter and haltere yellow, knees and basal part of fore tibia yellowish, first antennal flagellomere about 2 times as long as wide, length of prementum about 2.2 times as long as high, mid tibia with 4-5 $p d$, hind margin of $5^{\text {th }}$ sternite narrow, surstylus slender in profile F. setitibia Wang, 2008

12. Mid tibia with 2 ad

- Mid tibia with 1 ad

13. Eye bare, frontal setae 8 , haltere dark brown at apex F.cylosternita Xue \& Wang, 1996

- Eye with long and brown hairs, frontal setae 10 , haltere brownish-yellow

\section{F. longiseta Wang, 2008}

14. Hind femur with a long $p v$ row, longest seta about 1.5 times as long as femoral diameter, proepimeral setae $6-8$, cerci parallel on outer margins F.abrupta Malloch, 1924

- Hind femur without $p v$ row; or if with, longest seta at most as long as femoral diameter $\quad 15$

15. Upper calypter darkbrown

- Upper calypter usually yellowish to brown; or if dark brown, postoccipital bristles absent 21

16. Haltere dark brown

- Haltere yellow

F. latihamata Xue, Gao \& Wang, 1996

17. Presutural acr biserial

- Presutural acr triserial

18. Hind femur with $2-3$ strong $a v$ in distal half 19

- Hind femur with 4 strong $a v$ in distal half, cerci with ventral margin medially convex (in posterior view) F. carbonella (Stein, 1895)

19. Hind femur with curved setae on posterior to posteroventral surface, pra about 2/3 length of notopleural setae, leg black

F. eremna Chillcott, $1961 \mathrm{~b}$

- Hind femur without curved setae on posterior to posteroventral surface, pra about 1/3 length of notopleural setae, knees and basal part of fore tibia yellowish

F. suberemna Wang, sp. n.

20. Hind femur with a multiserial row of setae on basal $2 / 3$ posteroventrally, longest ones equal to femoral diameter, frons about 2 times as wide as diameter of anterior ocellus, cerci gradually becoming narrower towards apex, tergite 9 with a long seta on posterior margin

F. alpina Pont, 1970

- Hind femur only with a row of hair-like $p v$ in basal half, longest ones shorter than femoral diameter, frons about 2.5-3 times as wide as diameter of anterior ocellus, cerci abruptly becoming narrower on distal $1 / 3$, the apex obvious curved towards caudad, tergite 9 without a long seta on posterior margin

F. uptiodactyla Wang, \& Xue, 1998

21. Mid tibia with $2 p d$

- Mid tibia with $1 p d$

22. Eye with distinct hairs, first antennal flagellomere about 2.5 times as long as wide, frontal setae $11-15$, prementum about 2.5 times as long as wide F. angusta Nishida, 1994

- Eye bare, first antennal flagellomere about 2 times as long as wide, frontal setae 8-9, prementum about 2 times as long as wide

F. similiserena Feng \& Xue, 2006

23. Abdominal tergites with a median longitudinal stripe 24

- Abdominal tergites with triangular marks 27

24. Fore tibia black at base, at most knees yellow

- Fore tibia yellow at base, all knees and basal part of all tibiae yellowish, cerci broad F. subsimilis Ringdahl, 1934

25. Postoccipital bristles present 26

- Postoccipital bristles absent, abdomen with thin greyish pollinosity

F. meridionalis Chillcott, 1961a

26. Proepimeral setae 2-3, cerci truncate on apical margin $\quad$ F. cinerea Chillcott, $1961 \mathrm{~b}$

- Proepimeral seta $0-1$, cerci strongly concave on apical margin

F. intermedia Chillcott, 1961a

27. Hind femur without distinct $p v$ row 29

- Hind femur with a row of $p v$ in basal half 28

28. Halteres brownish-yellow, frontal setae 9

F. peneserena Nishida, 1972

- Knob of halteres black, frontal setae 6-7

F. caucasica Pont, 2015

29. Fronto-orbital plate visible in profile $\quad 30$

- Fronto-orbital plate narrow, not visible in profile, hind tibia with numerous setulae on posteroventral surface

F. montana Nishida, 1975 
30. Postoccipital bristles present, occipital bristles long and irregular

- Postoccipital bristles absent, occipital bristles short and regular, abdomen with heavy brown pollinosity F. immaculata Malloch, 1913 31. Haltere brownish-yellow, width of $5^{\text {th }}$ sternite at most subequal to its length

F. serena (Fallén, 1825)

- Haltere dark brown, width of $5^{\text {th }}$ sternite obviously broader than its length

\section{F. kelaenohaltera Wang \& Sun, 2010}

Acknowledgements. We thank Dr. Adrian C. Pont, Oxford University Museum of Natural History, Oxford, UK, and Dr. Kazumi Nishida, Kobe Institute of Health, Kobe, Japan, for providing us with many important papers. We are also very grateful to Jing Wang, Shuchong Bai Paleontology Institute of Shenyang Normal University, Shenyang Province, China, for his invaluable help in this study. This study was funded by the National Natural Science Foundation of China (31272347, 30770252, 31071957).

\section{References}

Chillcott, J. G. 1961a: A revision of the Nearctic species of Fanniinae (Diptera: Muscidae). - The Canadian Entomologist, Supplement 14: 1-295.

Chillcott, J. G. 1961b: Ten new species of Fannia R.-D. (Diptera: Muscidae) from the Palaearctic and Oriental Regions. - The Canadian Entomologist 93: 81-92.

Fallén, C. F. 1825: Monographia Muscidum Sveciae. Part.VIII. Berlingianis, Lundae [= Lund] 73-80.

Feng, Y. \& Xue, W. Q. 2006: Six new species of genus Fannia R.-D. from Sichuan, China (Diptera: Fanniidae). - Acta Zootaxonomica Sinica 31(1): 215-223.

Hennig, W. 1965: Vorarbeiten zu einem phylogenetischen System der Muscidae (Diptera: Cyclorrhapha). Stuttgarter Beiträge zur Naturkunde 141: 1-100.

Malloch, J. R. 1913: Notes on some American Diptera of the genus Fannia, with descriptions of new species. Proceedings of the US National Museum 44: 621631.

Malloch, J. R. 1924: Exotic Muscaridae (Diptera) VII. The Annals and Magazine on Natural History (9)13: 409-424.

McAlpine, J. F. 1981: Morphology and terminology adults. - In: McAlpine, J. F., Peterson, B. V., Shewell, G. E., Teskey, H. J, Vockeroth, J. R. \& Wood, D. M (Coords): Manual of Nearctic Diptera 1: 9-63. Research Branch, Agriculture Canada, Canada. 674 pp.

Meigen, J. W. 1826: Systematische Beschreibung der bekannten europäischen zweiflügeligen Insekten 5: 1412. Schultz, Hamm.

Nishida, K. 1972: One new and three newly recorded species of the genus Fannia from Japan (Diptera: Musci- dae). - Scientific Reports Kanazawa University 17(1): 25-30.

Nishida, K. 1975: Six new and one newly recorded species of the genus Fannia (Diptera: Muscidae) from Taiwan, with a key to species. - Kontyû Tokyo 43(3): 364-380.

Nishida, K. 1994: The Fanniidae from Nepal (Diptera). Japanese Journal of Sanitary Zoology, Supplement 45: 81-89.

Pont, A. C. 1965: The mollissima-subgroup of Fannia Robineau-Desvoidy, with the description of a new species from Burma and a revised key to species (Diptera: Muscidae). - Annals and Magazine of Natural History (13)7: 757-767.

Pont, A. C. 1970: A new species of Fannia Robineau-Desvoidy from the Alps (Ins., Diptera, Muscidae). - Berichte des Naturwissenschaftlich-medizinischen Vereins in Innsbruck 58: 343-346.

Pont, A. C. 2015: Description of a new species of Fannia Robineau-Desvoidy, 1830 (Diptera: Fanniidae) and distribution records of the genus from the Caucasus Mountains. - Zootaxa 3956(1): 140-148.

Ringdahl, O. 1934: Översikt av svenska Fannia-arter (Muscidae). - Entomologisk Tidskrift 55: 105-121.

Robineau-Desvoidy, A. J. B. 1830: Essai sur les Myodaires. - Mémoires présentés par divers savants 1'Académie des science de l'Institut de France 2: 1-813.

Rondani, C. 1866: Anthomyinae Italicae, collectae distinctae et in ordinem dispositae. - Atti della Societá italiana scienze naturali e del Museo Milano 9: 68-217.

Rozkošný, R., Gregor, F. \& Pont, A. C. 1997: The European Fanniidae (Diptera). - Acta scientiarum naturalium Academiae scientiarum Bohemicae, Brno 31: 180.

Stein, P. 1895: Die Anthomyidengruppe Homalomyia nebst ihren Gattungen und Arten. - Berliner Entomologische Zeitschrift 40: 1-141.

Wang, B. F., Wang, M. F., Xue, W. Q. \& Chang, L. 2006: Studies on fauna of Fanniidae in Dongbei Region of China (Diptera: Fanniidae). - Chinese Journal of Pest Control 22(8): 554-557.

Wang, M. F. \& Liu L. 2008: A review of the serena-subgroup of the Fannia serena group (Diptera: Fanniidae). - Oriental Insects 42: 269-284.

Wang, M.F. \& Sun, C. 2010: A new species of the genus Fannia Robineau-Desvoidy from China (Diptera, Fanniidae). Acta Zootaxonomica Sinica, 35(4): 756759.

Wang, M. F. \& Xue, W. Q. 1998: A new species of genus Fannia from Shanxi, China (Diptera: Fanniidae). Acta Entomologica Sinica 41 (2): 184-186.

Wang, M. F., Zhang, D. \& Xue, W. Q. 2006: A review of the F. serena-subgroup of Fannia Robineau-Desvoidy (Diptera: Fanniidae), with the description of two new species from China. - Zootaxa 1162: 33-43.

Xue, W. Q. \& Chao, C. M. (eds) 1998: Flies of China. Liaoning Science and Technology Press, Shenyang. 2, 480 pp. 